\title{
The Adaptative Studies on Teacher's Roles in Bilingual Classroom Teaching
}

\author{
Xiaoqian Duan \\ English Department, Qingdao University of Science and Technology, Qingdao, China \\ Suzhen Ren \\ Teaching Affairs Office, Qingdao University of Science and Technology, Qingdao, China
}

\begin{abstract}
Based on Jef Verschueren's, Yu Guodong localizes it into the Adaptation Model to analyze and explain the English-Chinese code-switching indicating that the reason why communicators choose two or more languages in the same communicative discourse is that they want to adapt to the linguistic reality, the social conventions, or the psychological motivations so as to reach the particular communicative goal. This echoes with the teaching practice language use in bilingual education and can help bilingual teachers to clarify their roles in classroom teaching to enhance the teaching effect.
\end{abstract}

Index Terms - adaptation theory, code-switching, bilingual teachers, roles

\section{INTRODUCTION}

Bilingual education has been implemented for nearly one decade in many Chinese universities and colleges ever since the issue of the Bilingual Teaching Course Reform Plan in 2001 striving to cultivate students' faculty to acquire expertise and skills and to strengthen their language application (Zhou Zhenzhong, 2004). Bilingual courses in China are instructed completely or partially in foreign languages, mainly English, aiming to make the students competent for international communication in academic activities (Zhang Zongrang, 2004). With the stimulus of The Curriculum Reform for Undergraduate Education in 11th Five -Year Plan, bilingual education has developed rapidly and continuously in China. However, the current study and implementation of bilingual teaching is not adequate yet, for researches on bilingual education mainly focused on the connotations and essentials of bilingual teaching, bilingual teaching material compilation and selection, bilingual teaching surroundings and resources, etc. The relevant research on bilingual classroom teaching has not been conducted sufficiently.

As the standardization goes, bilingual teachers should possess the fluency in English and expertise in the subjects. Since bilingual education in China is just in its early stage, it is impossible to train great numbers of proficient bilingual teachers to meet the professional qualifications in a short time. In reality, the bilingual teachers are from two fields: teachers who used to teach English majors and subject teachers with higher English level. The former ones are capable of language teaching, but unfamiliar with specialized knowledge, while some subject teachers are professional in their domains but with comparatively low language proficiency. Therefore, teachers who can meet both the linguistic and the professional demands are quite few. Great numbers of problems mainly related to the bilingual teachers remain unsolved, including a severe shortage of competent bilingual teachers, the gap of proper teaching methodology, the random use of teaching language on class, no switch between two languages, the ignorance of the students' response caused by their different language levels and that many bilingual teachers conduct their teaching only by translating the English texts or explaining grammar and vocabulary to students.

Hence, bilingual education and bilingual teachers are in urgent need of practical and specific pedagogic methodologies and perspectives which can help eliminate the bottleneck of bilingual teaching development.

\section{THE ADAPTATION THEORY AND ADAPTATION MODEL}

On bilingual classroom, the teachers have to alternate between Chinese and English frequently, which is very close to the term code-switching defined by Auer in 1998 that the alternating use of two or more languages by bilingual or multilingual speakers within one conversational episode, either in the same conversational turn or in consecutive turns. Thus, the practice in bilingual class is much the same as the code-switching as far as language application is concerned.

Among the linguistic approaches including sociolinguistics, grammatical, conversational analysis, psycholinguistics and pragmatics which have tried to explore code- switching since 1970s, pragmatic approach in 1980s explains the process of code-switching in a dynamic context taking into account the full complexity of the linguistic, social, psychological, cognitive and cultural factors, and thus may explain the problems of the systematical and functional aspects of code-switching comprehensively and satisfactorily (He Ziran \& Yu Guodong, 2001).

And in 1999, Jef Verschueren put forward a Linguistic Adaptation Theory in his book Understanding Pragmatics from the pragmatic approach, which further developed his theory in Pragmatics as a Theory of Linguistic Adaptation in 
1987. He took the process of language use as a dynamic choosing process. Language use must consist of the continuous making of linguistic choices, consciously or subconsciously, for language-internal (i.e. structural) and language-external reasons. That kind of choices can be understood in three hierarchically related characteristics: variability, negotiability and adaptability which are the basic properties of all human natural languages. Adaptability is the property which enables human beings to make negotiable linguistic choices from a variable range of possibilities in such a way as to approach points of satisfaction for communicative needs. To explain the notion of adaptability, four aspects must be taken into consideration: contextual correlates of adaptability, structural objects of adaptability, and dynamics of adaptability and salience of adaptation process. Thus, pragmatic approach is needed to explain the process of code-switching comprehensively not only from the aspects of social factors, psychological conceptual factors and linguistic ones separately but combine these factors together.

The linguistic adaptation theory means that using language must consist of the continuous making of linguistic choices, consciously or unconsciously, for language- internal (i.e. structural) and language-external reasons (Verschueren, 1999). Some characteristics in the process of choice making are: (1) Choices are made at every possible level of structure which ranges from phonetic, phonological, morphological, syntactic, lexical and semantics, etc.; (2) The language users do not only choose forms but also language strategies; (3) The term "making choices" may be misleading in the sense that it may invariably suggest a conscious act. In other words, the process of choice making may happen with different degrees of consciousness; (4) Choices are made both in producing and in interpreting an utterance, and both types of choice-making are of equal importance for the communication flow and the way in which meaning is generated; (5) Language users have no freedom of choice between choosing and not choosing, for once involved in the language process, the language user has to choose the most eligible and needed communication elements; (6) Choices are not equivalent for language users, because choice making is influenced and restricted by social and cultural factors; (7) Choices evoke or carry along their alternatives.

The process of 'making of choices' can be understood in terms of the three hierarchically related properties which language possesses: variability, negotiability and adaptability. Among the three properties of language, variability is the language property which defines the range of possibilities from which choices can be made (Verschueren, 1999). Negotiability is the property responsible for the fact that choices are not made mechanically or according to strict rules or fixed form-function relationships, but rather on the basis of highly flexible principles and strategies. Adaptability is the property which enables human beings to make negotiable linguistic choices from a variable range of possibilities in such a way as to approach points of satisfaction for communicative needs (Verschueren, 1999). The three notions do not represent topics of investigation, but merely interrelated properties of the overall object of investigation for linguistic pragmatics and the meaningful functioning of language. Their hierarchical ranking serves as a concept tool to understanding pragmatic phenomena.

\section{Contextual Correlates of Adaptability}

First, contextual correlates of adaptability have to be identified. This means that language choices must adapt the communicative context (Verschueren, 1999). The contextual correlates of adaptation could be sketched as the following figure:

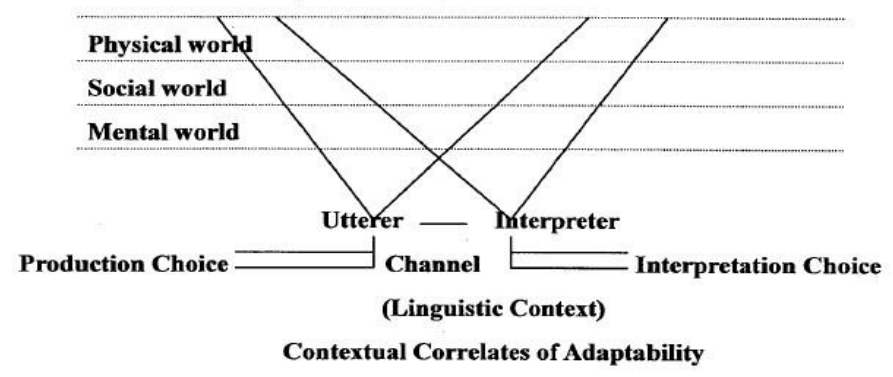

Utterer $(\mathrm{U})$ and interpreter $(\mathrm{I})$ are the focal points of the context. Without utterers' and interpreters' participation, and the functioning of their minds, there is no language use. The lines in the figure converging in $U$ and $I$ can be seen as forming "lines of vision". Every aspect of context within the lines of vision can function as a correlate of adaptability. U and I are presented as focal points because the contextual aspects of the physical, social and mental worlds do not usually start to play a role in language use until they have somehow been activated by the language users' cognitive process. U and I inhabit different worlds, but there are some overlaps between those worlds. The perspective differs, and the common background formed by the overlapping area looks different from each different perspectives. It also shows that communicators make different choices to adapt to contexts, with $\mathrm{U}$ making production choices while the interpreter is making interpretation choices.

The mental world mainly includes utterers' and interpreters' personality, emotions, beliefs, desires, intentions, and motivations. It is includes utterer voice and interpreter roles and that is why "mental world" at the base. Social world refers to principles and rules of social situation, social surroundings and situation-surroundings combinations. Communicators must obey them in communication activities. Among all the factors in the social world, culture is of 
great importance. Time and space are the most visible features in the physical world. Temporal reference is useful to make a distinction between event time, time of utterance and reference time (Verschueren, 1999). While spatial reference is usually relative to perspective, which can be either utterer space or reference space (the latter defined as having a deictic center distinct from the perspective of the utterer). Therefore, the range of all the ingredients of the communicative context goes from aspects of physical surroundings to social relationships between speakers and hearers and aspects of interlocutors' state of mind. In conclusion, the communicators will be affected by all the factors mentioned above when choosing communication types and language. The context here is not a fixed type. According to Verschueren, "contexts are generated in language use", therefore, his perspective about context is dynamic.

\section{Structural Objects of Adaptability}

"Structural objects of adaptability include structures, in the strict sense, at various layers or levels of organization as well as principles of structuring" (Verschueren, 1999: 115). These two parts are always interdependent and inter-adaptable. In a word, structural objects of adaptability involve the making of choices at the overarching structural levels of languages, codes and styles. Codes refer to the distinguishable variants of a language, involving sets of choices which are geographically, socially or situation ally based. Styles are the dimensions of formality and informality.

From the entire range of utterance-building ingredients, the process can be indicated in every layer which includes sound structure (intonation, rhythm, stress, voice quality, etc.), morphemes and vocabulary, clauses and sentences, propositions and supra-sentential units, etc.

From the entire range of utterance and utterance clusters, the two types of speech acts and discourse types are included.

"In the light of utterance-building principles, choices are at the levels of sentential and supra-sentential utterance building and utterance clusters, which are guided by some strategies to establish and maintain coherence "(Verschueren, 1999:145).

\section{Dynamics of Adaptation}

The dynamics of adaptation is central to the process of (inter) adaptation in language use or to the meaningful functioning of language (Verschueren, 1999). Concerning with impact of contextual correlates and structural objects of adaptability, no doubt, the dynamics of adaptation is the central task of most specific pragmatic investigations. Questions also have to be answered about the ways in which communication principles and strategies are used in the making and negotiating choices of production and interpretation. Three particular factors should be mentioned:

The first one is the correlation between dynamics and the temporal dimension. At the micro level, the interlocutors' memory imposes the considerable time-related processing constrains and the communicative processing itself involves planning. At the macro level, earlier stages of development of languages and linguistic conventions are no longer readily accessible to the language user. Language, as time changes, is not accidental, but with the dynamic adaptation in language use.

The second one is the correlation between dynamics and context since the communication takes place between human beings for social relationship. In order to maintain their social status, some factors impact their language use: the group identities, the pace at which information is exchanged, the types of information and the social status, etc.

The third one is the correlation between dynamics and structure is linearity, a powerful constraint in communication phenomenon which does not fully determine the shape of the dynamics of language use. The interlocutors can move back and forth along the basic linear dimension at any stage in the process of meaning generation.

\section{Salience of Adaptation}

The salience of the adaptation process is that all linguistic choices are made with equal degree of consciousness, but some are highly motivated while others are rather automatic with the functioning of human cultural mind (Verschueren, 1999). Considering that the present study on bilingual classroom code-switching is from the teacher's point of view, the contextual correlates will focus on the utterer's perspective. The four tasks of adaptability can be seen as necessary ingredients in all adequate pragmatic perspectives on any given linguistic phenomenon. However, these four tasks for pragmatic investigation are not to be considered on a par with each other. A combination of contextual correlates and structural objects of adaptability can be used to define the locus of adaptation phenomena; the dynamics of adaptability unfolds the adaptive processes between context and structure; the salience of adaptation processes refers to the status of the making of those processes in relation to the cognitive apparatus.

As mentioned above, both language use and understanding are the process of choosing unceasingly made by the communicators. The contextual correlates show the language instructors what language choice they should adapt to, while the dynamics of the adaptability shows that the teaching process is a dynamic not a static one and that the structure of language and the context is a dynamic process.

As Yu Guodong (2001) claims that pragmatic model is intended to offer a better answer to the question of what people do when switching codes, or what they do by means of switching codes. Therefore, the characteristic of pragmatics is that all the language processes are dynamic, and it combines the phenomena of language description and explanation and it reveals the language dynamic process.

Based on Verschueren's adaptation theory, Yu Guodong (2001) localizes the adaptability of Chinese and English code-switching and creatively came up with the Adaptation Model. According to Yu Guodong's Adaptation Model for Chinese/English code-switching, the reason why communicators choose two or more languages in the same 
communicative discourse is that they want to adapt to the linguistic reality, the social conventions, or the psychological motivations so as to reach the particular communicative goal. Moreover, this model can provide a stronger explanatory power to code-switching with full complexity of language factors. It can be chosen as a linguistic strategy to realize a certain communicative goal, since no other linguistic or non-linguistic means can function in the same way or achieve the same communicative effects. The Adaptation Model of code-switching can be summarized as follows:

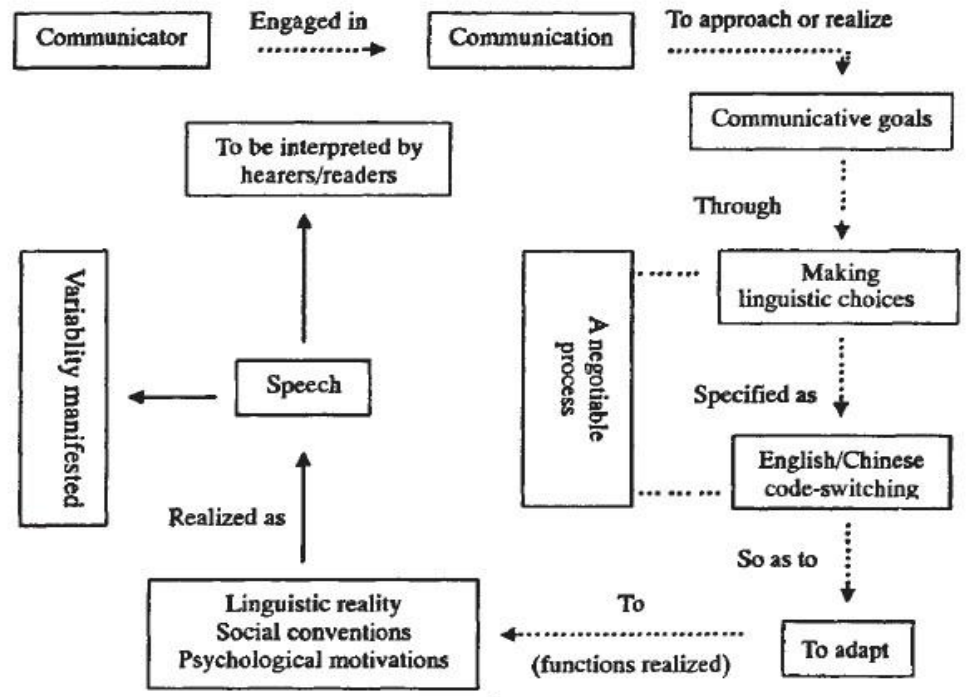

The Adaptation Model of code-switching (Yu Guodong, 2001)

Communicators switch codes in their communication to adapt to three objects: the linguistic reality, social conventions and psychological motivations. Communicator's adaptation and choice making are realized in speech, which is featured by the property of variability in terms of both linguistic elements and structures and discourse types. Ultimately, it will be interpreted by the hearer/reader. The success of the communication is up to the speaker and hearer's mutual involvement in communication, that is, from the time when the utterer/writer produces his or her utterance with specific intentions to the time when the hearer/writer perceives and interprets them (Yu Guodong, 2001).

\section{Teacher'S Roles in Binlingual Classroom Teaching}

As far as Bilingual teaching is concerned, the communicative process involves two key factors that greatly affect the effect of the communication---bilingual teachers and students. On bilingual classrooms, teachers are multifunctional in the teaching practice. Harmar (1991) has given one kind of categorization: teachers in classroom can play the roles of a controller (in complete charge of the class); an assessor (for example, to see how well they are performing or how well they performed); an organizer (for example, to organize an activity, to tell or give instructions); a promoter (for example, to encourage students to participate or to make suggestions); a participant (to participate as an equal in an activity). And from the perspective of adaptability, bilingual teachers play their roles in the dynamic process of interactions to adapt to the classroom context.

1. "Linguistic reality refers to the real existence and nature of a certain language. The real existence of a language refers to the linguistic elements and linguistic structures of that language, and the real nature of a language refers to the features and properties of those linguistic elements and linguistic structures of that language in its own right and/or compared with other natural languages." (Yu, 1999)

Code-switching as the adaptation to linguistic reality refers to the use of two or more languages or language varieties that only occurs for linguistic reasons and its performance is based on the language-internal reasons completely. Therefore, code- switching is considered as the means of linguistic adaptation in general. It is a goal -directed dynamic process, in which language choices are made to adapt to certain objects in order to realize their communicative aims in a given context.

At present, most bilingual programs are carried out in science subjects, some of the textbooks were written by Chinese scholars in English containing the latest information in their fields and some of the textbooks are brought in from world famous universities. For non-English major students, the academic language may be difficult to understand. Consequently, students are overloaded by the large reading tasks which affect their speed and effect of learning. To this degree, the most important communicative function that code-switching has is filling the linguistic gap between the languages involved and makes the communication smooth. Code-switching tends to be a good choice as the communicative strategy. The teachers should promptly adapt to the linguistic reality in classroom context. Specifically, bilingual teachers should create a real bilingual environment and demonstrate standard pronunciation and idiomatic expressions on the one hand to help students immerse in the linguistic environment, and on the other, utilize 
code-switching, mainly from English to Chinese to facilitate students' understanding and to wipe out the hindrance in students' learning by making elaborate illustrations of the obscure expressions in the textbooks.

As a good communicator, when confusion-causing terminologies appear for instance, bilingual teachers should quickly notice students' reaction to the unclear expressions and explain the terminologies first in English and then switch to Chinese to give its equivalence so as to eliminate misunderstanding and misinterpretation of the professional terminologies. This will obviously enhance students' acquisition of professional vocabulary especially for those who are carrying out scientific research and writing papers.

Therefore, bilingual teachers in such contexts function as conscious language-demonstrators to show language norms to standardize students' linguistic performance on class and try to avoid random or substandard use of language so as to adapt to the requirements of bilingual education to enhance students' English proficiency; and meanwhile dynamic translators/interpreters mainly from English into Chinese to help clarify the contents and solidify the comprehension of the content necessarily, especially for those students with low English levels to strengthen their professional learning.

2. Social settings and institutions impose many types of linguistic acts; they can be performed, or even can determine the 'performability' of certain acts under specified circumstances (Verschueren, 1999). Code-switching as the adaptation to the social conventions stands for the use of code-switching related to the communicator's consideration of social culture, customs and conventions, which means the common way of thinking and behavior that are socially normal and acceptable by the majority of a given society.

Social convention seems to be a huge net which restraining people's behavioral and mental activities, therefore, communicators have to pay enough attention to it in communicative process, and code-switching is a practical strategy (Yu, 1999). The roles teachers play on class can be categorized into two types according to social consensus: the respected role in society mainly owing to the possession of civilized minds and wide professional knowledge and the instructive role in class teaching. These are the two roles the teachers have to adapt to. Hence, the bilingual teachers have to use polite and civilized language in teaching and switch from Chinese to English to avoid some embarrassing or impolite words in the classroom to adapt to their social role especially when some sensitive topics are referred to---sex and politics for instance.

In the process of classroom teaching, bilingual teachers have to adapt to their social role to preserve the positive image of teachers, meanwhile, a knowledge-spreader to transmit knowledge, an evaluator commenting on students' performance, an organizer and participant when carrying out an activity to adapt to their teaching role.

3. Compared with the two objects of adaptation mentioned above, the adaptation to psychological motivations is more active, for communicators have to passively realize their intentions through adapting to linguistic reality and social conventions which are accepted by the majority of society, however, the communicative psychological motivations are more private and variable. In bilingual classrooms, the teachers' motivations influence or even determine not only what to say but also how to say, namely, how to construct teachers' discourse to realize certain purpose (Wang, 2003). The motivations consist of giving examples, making explanations, providing thinking strategy, enlivening atmosphere, giving emphasis, facilitating understanding, making generalization, etc. When the bilingual teachers want to emphasize on some important content, they should switch from one language to another to arouse students' attention and repeat it for times. When the bilingual teachers want to facilitate understanding of the obscure English expressions appearing in reading or speaking, they should switch to Chinese language to explain it completely and exhaustively. When the bilingual teachers want to generalize some points and give examples, they could have a stop and switch to some non-linguistic behavior, clear their throats for instance to reach a satisfactory communicative goal. To this degree, the motivations of the teachers are complex and changeable, during the teaching process, bilingual teachers have to utilize code-switching as a linguistic strategy dialectically to adapt to their motivations by playing a comprehensive and dynamic role. Hence, bilingual teachers are the real controllers and coordinators who take charge of the whole class in the teaching process.

\section{CONCLUSION}

In classroom teaching, bilingual teachers have to intentionally realize their teaching purposes by making choices of language and communicative strategies. They may switch code to adapt to one or more objects either consciously or subconsciously. Only by making linguistic and communicative choices with salient consciousness, could the bilingual teachers reach ideal and satisfactory effects. And the bilingual teachers should utilize code-switching variably and negotiably in the dynamic process to adapt to the roles they should take in bilingual classroom teaching. It may enhance the language application ability of bilingual teachers so as to achieve a better effect of bilingual classroom teaching, and hence to reach the goal of improving the bilingual teaching quality.

\section{REFERENCES}

[1] Auer, P. (1998). Introduction: "Bilingual Conversation" revisited in Auer. P's Code-switching in Conversation. London: Routledge.

[2] Auer, P. (ed). (1998). Code-switching in Conversation: Language, Interaction and Identity. London: Routledge.

[3] He Ziran \& Yu Guodong. (2001). Researches on Codeswitching. Modern Foreign Language, 24(1), 86-95.

[4] Verschueren, J. (1987). Pragmatics as a Theory of Linguistic Adaptation Ipra Working Document 1. Antwerp: International 
Pragmatics Association.

[5] Verschueren, J. (1999). Understanding Pragmatics. London, New York, Sydney, and Auckland: Arnold.

[6] Wang Binhua. (2003). Bilingual Education and Bilingual Teaching. Shanghai: Shanghai Foreign Language Education Press

[7] Yu Guodong. (2001). The Chinese/English Codeswitching as Realization of Linguistic Adaptation Abstract. Gungdong: Guangdong University of Foreign Studies.

[8] Zhang Zongrang. (2004). A Research on the Gain and Cost of Bilingual Teaching of Non-English-Oriented Courses. Teaching English in China, 78-79.

[9] Zhou Zhenzhong. (2004).Views and Practices on Bilingual Teaching. Journal of Shaanxi Normal University (Philosophy and Social Sciences Edition), 33, 426-428.

[10] http:// www.btrc.edu.cn (accessed 12/7/2013).

Xiaoqian Duan was born in 1980 Qingdao, Shandong Province, China. She graduated from Ocean University of China in 2003 with the Master's Degree majoring in Foreign Linguistics and Applied Linguistics.

She is now teaching English as a lecturer in Foreign Languages School of Qingdao University of Science and Technology.

Suzhen Ren was born in 1960 Qingdao, Shandong Province, China. She graduated from Shandong Normal University with the Bachelor's Degree majoring in English.

She is now a professor working at Teaching Affairs Office of Qingdao University of Science and Technology. 